\title{
Natural Products for the Therapy of Proteinopathies Underlying the Neurodegenerative Conditions: Protein Misfolding and Fibrillization in Alzheimer's Disease and Parkinson's Disease
}

\author{
Robert P Weinberg*, Vera V Koledova, Anthony J Sinskey and ChoKyun Rha \\ Department of Biology, Massachusetts Institute of Technology, USA
}

*Corresponding author: Robert P Weinberg, Department of Biology, Massachusetts Institute of Technology, 77 Massachusetts Ave, Cambridge, USA.

To Cite This Article: Robert P Weinberg. Natural Products for the Therapy of Proteinopathies Underlying the Neurodegenerative Conditions: Protein Misfolding and Fibrillization in Alzheimer's Disease and Parkinson's Disease. Am J Biomed Sci \& Res. 2019 - 3(3). AJBSR.MS.ID.000675. DOI: 10.34297/AJBSR.2019.03.000675

Received: May 24, 2019 | Published: June 12, 2019

\section{Introduction}

Significant progress has been made in our understanding of dysregulated proteostasis and protein misfolding which underlie the pathogenesis of such neurodegenerative diseases as Alzheimer's disease (AD) and Parkinson's disease (PD). In the 1990s the kinetics of $\beta$-amyloid $(A \beta)$ fibrillization was well characterized $[1,2]$. Epidemiology had shown that mutations in amyloid precursor protein (APP) or the beta- and gamma-secretases which elevate the level of $A \beta$ in the brain, as well as mutations which increase the propensity for $A \beta$ to polymerize, are strongly associated with the development of Alzheimer's disease. Oligomers of $A \beta$ are more neurotoxic than the monomers [3-5]. These observations suggested that molecules which would interfere with polymerization and fibrillization might slow the progression of AD. During the testing of natural compounds, Thioflavin-T (Th-T) was often used to monitor the state of $A \beta$ polymerization [6].

The tendency for many proteins and peptides to convert from their native functional state into intractable amyloid aggregates was found to underlie multiple human disorders including Alzheimer and Parkinson diseases, type II diabetes, prion disease and several systemic amyloidosis (e.g. A $\beta, \alpha$, PrP, $\tau$, IAPP, TDP-43, p53) [7-15]. Multiple therapeutic strategies have been employed to find disease-modifying agents against amyloidosis [16]. Some natural compounds found in the diet have anti-amyloid effects and may reduce the risk for AD and T2D $[17,18]$. Epidemiologic studies have suggested that diets with a high intake of flavonoids and polyphenolic compounds may have protective effects against $A D$, T2D and dementia [19-21]. Several polyphenols have progressed to clinical trials for the treatment of $\mathrm{AD}$ including resveratrol, curcumin, epigallocatechin-3-gallate (EGCG) and palm fruit bioactive $[19,22,23]$.

Abbreviations: $A \beta$ : Beta-Amyloid; $\alpha$ : Alpha-Synuclein; $\tau$ : Tau Protein; PRP: Prion Protein; IAPP: Islet Amyloid Peptide; TDP-43: TAR DNA-Binding Protein 43; P53: Tumour Suppressor P53; T2D: Type 2 Diabetes Mellitus; AD: Alzheimer's Disease; PD: Parkinson's Disease; ALS: Amyotrophic Lateral Sclerosis

These polyphenols, demonstrating a range of anti-inflammatory, antioxidant and metal chelating bioactivities, have served as structural backbones in the computational design of novel drugs $[24,25]$. A PubMed literature review of natural compounds which modulate amyloid aggregation revealed 72 compounds, of which 44 are phenolic compounds including 16 flavonoids, 4 anthraquinones, 13 alkaloids (including 3 pyridines, 3 indoles, 2 porphyrins), steroids and terpenes [26].

Epidemiologic studies of diets have shown that the regular ingestion of curcumin, myricetin, EGCG, along with green tea polyphenols is associated with healthy cognitive function $[19,27,28]$. Cohort studies on the moderate consumption of red wine suggest that resveratrol reduces the risk of dementia, $\mathrm{AD}$ or cognitive decline associated with aging [21,29] Among the 72 anti-amyloid compounds identified in the PubMed search are many phenolic compounds which are found in brain-healthy diets associated with reduced risk of aging-associated amyloid pathologies [19,30,31]. These compounds include: EGCG and myricetin found in green tea; curcumin found in turmeric; caffeic acid and rosmarinic acid found in culinary herbs; oleuropein and oleocanthal found in olive 
oil; resveratrol found in red wine and grapes; genistein found in legumes; and cinnamaldehyde found in cinnamon. Investigations into the mechanism of action by which these compounds inhibit amyloid aggregation show that some exert their effects through the formation of covalent bonds [32-39] and others exert their effects through non-covalent interactions [40-57].

The proteinopathies, involving protein misfolding and aggregation into toxic fibrillar deposits, are common to multiple neurodegenerative conditions including AD, PD, ALS, TDP-43, IAPP, prion diseases as well as to such systemic disorders of T2D and systemic amyloidosis [58-62]. Clinical trials aimed at reducing the level of toxic misfolded protein aggregates have not been successful over the past decade, perhaps due to a futile intervention following irreversible and irreparable cell and tissue damage. More promising is the potential for preventing the organ damage in the first place, through the regular intake of a diet rich in phenolics, which have dual activity as both amyloid aggregation inhibitors and as antioxidants.

Beta amyloid $(A \beta)$ and tau $(\tau)$ aggregates are pathognomonic for AD [63]; alpha-synuclein ( $\alpha$ s) deposits are seen in PD [64]; prion diseases and transmissible spongiform encephalopathies (TSE) present with misfolded prion protein (PrPSC) [65]; aggregates of superoxide dismutase 1 (SOD-1) and TAR DNA-binding protein 43 (TDP-43) characterize ALS [66-68]; and fronto-temporal dementia (FTD) also manifests aggregates of TDP-43 [69]; Huntington's disease manifests aggregation of glutamine-rich (polyQ) Huntingtin protein (htt) [70]. The toxic protein aggregates dysregulate the cellular metabolism and activate a complex cascade of events which may lead to acute inflammation or apoptosis. The amyloid aggregates may also block proteasomal activities and cause a marked disturbance in proteostasis. Beta-sheet-rich proteins jam the entry site to the catalytic core, thereby blocking the proteasome system [71-73]. Often the autophagy system seems impaired in these diseases with accumulation of autophagic vacuoles [74-76]. The toxic aggregates also disrupt permeability of cell membranes, impair mitochondrial function, increase reactive oxygen species, induce acute inflammation and disrupt proteostasis. The protein aggregates also expose hydrophobic portions which interact abnormally with other cellular proteins, which results in their sequestration and loss of normal function $[61,77,78]$.

Epigallocatechin-3-gallate (EGCG) is a flavanol found in green tea leaves [79] EGCG has demonstrated neuroprotective, antioxidant, antibacterial and antitumor activity in vitro and in vivo $[80,81]$ EGCG reduces the aggregation and toxicity of a wide range of proteins involved in proteinopathies. Some papers report that EGCG acts at an early stage of aggregation by binding with the proteins in a non-sequence specific manner [82]. Evidence suggests that it may bind to and stabilize unfolded conformations of $A \beta$ and $\alpha$ s, thereby reducing fibrillation and re-directing the proteins from the aggregation cascade to off-pathway amorphous non-toxic aggregates.45 EGCG also binds to partially misfolded tau [83]. Through its multiple mechanisms of action on inhibiting amyloid aggregation suggests its potential use in preventive clinical trials on $\mathrm{AD}$.
Curcumin is a biphenolic compound found in Curcuma longa, the Indian spice turmeric used in curry dishes, has strongly documented anti-inflammatory and antioxidant properties [84,85]. Based on its general activity inhibiting amyloid aggregation, Curcumin has shown beneficial effects in AD, PD, T2D and prion diseases $[84,86,87]$ Clinical trials are underway for Curcumin for $\mathrm{AD}$ and T2D. Curcumin directly binds to $A \beta$ and inhibits its aggregation in vitro [88] and in vivo [89]. Curcumin also disaggregates peptides from toxic aggregates.

Resveratrol is a natural phytoalexin stilbenoid polyphenolic compound found in grapes, berries, soybeans, peanuts and red wine. Resveratrol inhibits the aggregation of $A \beta$ through selective transformation of the oligomers and shuttling them into off-pathway species which are unable to aggregate [90]. Resveratrol can bind multiple conformations of $A \beta$ including $A \beta 42, A \beta 40$ and fibrillar $A \beta$ [91]. Resveratrol is able to disaggregate $A \beta$ from $A \beta 42$ fibrils [92] In cell culture, resveratrol reduces the hyperphosphorylation of tau proteins [93]. In transgenic AD murine models, resveratrol has been shown to reduce amyloid plaque deposition without directly affecting the processing of APP $[94,95]$.

In the transgenic murine $\mathrm{AD}$ models, resveratrol also:

1. Improves cognitive function [96,97],

2. Protects permeability of the blood-brain barrier [98],

3. Reduces acute inflammatory response through a decrease in microgliosis, and

4. Reduces the generation of reactive oxygen species (ROS) $[99,100]$.

Botes and Sinskey have observed that Palm Fruit Bioactive, comprising a polyphenol-rich extract from the Elaeis guineensis, reduce the cytotoxicity of aggregated $\alpha$-synuclein in a transgenic yeast rescue assay [101]. Other promising natural agents with potent anti-amyloid aggregation properties include: Apigenin, Fisetin, Kaempferol, Morin, Quercetin, Myricetin, Brazilin, Gallic acid, Oleocanthal, oleuropein, oleuropein aglycone, Orcein, Rosmarinic acid, Tanshinones, and Tannic acid. These natural compounds have been undergoing extensive investigation for their potential in preventing or reducing the proteinopathies, but a more detailed discussion of them is beyond the scope of this mini review.

\section{Conclusion}

The clinical trials with these natural compounds over the past decade have been disappointing but this may be the result of attempting to overcome irreversible and irreparable damage to the brain. We must consider implementing a diet rich in these natural anti-amyloid compounds early in life to prevent the neurotoxicity of these amyloid aggregates and thus prevent the inception and progression of these devastating neurodegenerative conditions. The answer may be in the prevention rather than the cure of these conditions.

\section{References}

1. Selkoe DJ (1997) Alzheimer's disease: genotypes, phenotypes, and treatments. Science 275(5300): 630-631. 
2. Lansbury PT (1997) Inhibition of amyloid formation: a strategy to delay the onset of Alzheimer's disease. Curr Opin Chem Biol 1(2): 260-267.

3. Lorenzo A Yankner BA (1994) Beta-amyloid neurotoxicity requires fibril formation and is inhibited by Congo Red. Proc Natl Acad Sci USA 91(25): 12243-12247.

4. Lambert MP, Barlow AK, Chromy BA, Edwards C, Freed R, et al. (1998) Diffusible, nonfibrillar ligands derived from Abeta1-42 are potent central nervous system neurotoxins. Proc Natl Acad Sci USA 95(11): 6448-6453.

5. Hartley DM, Walsh DM, Ye CP, Diehl T, Vasquez S, et al. (1999) Protofibrillar intermediates of amyloid beta-protein induce acute electrophysiological changes and progressive neurotoxicity in cortical neurons. J Neuroscience 19(20): 8876-8884.

6. Findeis MA (2002) Peptide inhibitors of beta amyloid Aggregation. Curr Top Med Chem 2(4): 417-423.

7. Chiti F, Dobson CM (2017) Protein misfolding, amyloid formation, and human disease: a summary of progress over the last decade. Annu Rev Biochem 86: 27-68.

8. Shankar GM, Li S, Mehta TH, Garcia-Munoz A, Shepardson NE, et al. (2008) Amyloid-beta protein dimers isolated directly from Alzheimer's brains impair synaptic plasticity and memory. Nat Med 14(8): 837-842.

9. Kayed R, Pensalfini A, Margol L, Sokolov Y, Sarsoza F, et al. (2009) Annular protofibrils are a structurally and functionally distinct type of amyloid oligomer. J Biol Chem 284(7): 4230-4237.

10. Stefani M, Dobson CM (2003) Protein aggregation and aggregate toxicity: new insights into protein folding, misfolding diseases and biological evolution. J Mol Med 81(11): 678-699.

11. Rivera JF, Costes S, Gurlo T, Glabe CG, Butler PC (2014) Autophagy defends pancreatic beta cells from human islet amyloid polypeptideinduced toxicity. J Clin Invest 124(8): 3489-3500.

12. Demuro A, Mina E, Kayed R, Milton SC, Parker I, et al. (2005) Calcium dysregulation and membrane disruption as a ubiquitous neurotoxic mechanism of soluble amyloid oligomers. J Biol Chem 280(17): 1729417300.

13. Stroo E, Koopman M, Nollen EAA, Mata-Cabana A (2017) Cellular regulation of amyloid formation in aging and disease. Front Neurosci 11(64).

14. Yang Y, Petkova A, Huang K, Xu B, Hua QX, et al. (2010) An Achilles' heel in an amyloidogenic protein and its repair: insulin fibrillation and therapeutic design. J Biol Chem 285(14): 10806-10821.

15. Westermark P, Andersson A, Westermark GT (2011) Islet amyloid polypeptide, islet amyloid, and diabetes mellitus. Physiol Rev 91(3): 795-826.

16. Eisele YS, Monteiro C, Fearns C, Encalada SE, Wiseman RL, et al. (2015) Targeting protein aggregation for the treatment of degenerative diseases. Nat Rev Drug Discov 14(11): 759-780.

17. Stefani M, Rigacci S (2013) Protein folding and aggregation into amyloid: the interference by natural phenolic compounds. Int J Mol Sci 14(6): 12411-12457.

18. Weinberg RP, Koledova VV, Shin H, Park JH, Tan YA, et al. (2018) Oil palm phenolics inhibit the in vitro aggregation of beta-amyloid peptide into oligomeric complexes. International Journal of Alzheimer's Disease p.12.

19. Yamada M, Ono K, Hamaguchi T, Noguchi-Shinohara M (2015) Natural phenolic compounds as therapeutic and preventive agents for cerebral amyloidosis Adv. Adv Exp Med Biol 863: 79-94.

20. Scarmeas N, Stern Y, Mayeux R, Luchsinger JA (2006) Mediterranean diet, Alzheimer disease, and vascular mediation. Arch Neurol 63(12): 1709-1717.

21. Luchsinger JA, Mayeux R (2004) Dietary factors and Alzheimer's disease. Lancet Neurol 3(10): 579-587.
22. Umeda T, Ono K, Sakai A, Yamashita M, Mizuguchi M, et al. (2016) Rifampicin is a candidate preventive medicine against amyloid-beta and tau oligomers. Brain 139(5): 1568-1586.

23. Fairus S, Leow SS, Mohamed IS, Tan YA, Sundram K, et al. (2018) A phase I single-blind clinical trial to evaluate the safety of oil palm phenolics (OPP) supplementation in healthy volunteers. Scientific Reports 8.

24. Savelieff MG, DeToma AS, Derrick JS, Lim MH (2014) The ongoing search for small molecules to study metal-associated amyloid-beta species in Alzheimer's disease. Acc Chem Res 47(8): 2475-2482.

25. Korshavn KJ, Jang M, Kwak YJ, Kochi A, Vertuani S, et al. (2015) Reactivity of metal-free and metal-associated amyloid-beta with glycosylated polyphenols and their esterified derivatives. Scientific Reports volume 5.

26. Velander P, Wu L, Henderson F, Zhang S, Bevan DR, et al. (2017) Natural product-based amyloid inhibitors. Biochem Pharmacol 139: 40-55.

27. Ardah MT, Paleologou KE, Lv G, Menon SA, Abul Khair SB, et al. (2015) Ginsenoside Rb1 inhibits fibrillation and toxicity of alpha-synuclein and disaggregates preformed fibrils. Neurobiol Dis 74: 89-101.

28. Velander P, Wu L, Ray WK, Helm RF, Xu B (2016) Amylin amyloid inhibition by flavonoid Baicalein: key roles of its vicinal dihydroxyl groups of the catechol moiety. Biochemistry 55(31): 4255-4258.

29. Arntzen KA, Schirmer H, Wilsgaard T, Mathiesen EB (2010) Moderate wine consumption is associated with better cognitive test results: a 7 year follow up of 5033 subjects in the Tromso Study. Acta Neurol Scand Suppl 190: 23-29.

30. Mishra S, Palanivelu K (2008) The effect of curcumin (turmeric) on Alzheimer's disease: an overview. Ann Indian Acad Neurol 11(1): 13-19.

31. Rigacci S (2015) Olive oil phenols as promising multi-targeting agents against Alzheimer's disease. Adv Exp Med Biol 863: 1-20.

32. Sato M, Murakami K, Uno M, Nakagawa Y, Katayama S, et al. (2013) Site-specific inhibitory mechanism for amyloid beta-42 aggregation by catechol-type flavonoids targeting the Lys residues. J Biol Chem 288(32): 23212-23224.

33. Zhu M, Rajamani S, Kaylor J, Han S, Zhou F, et al. (2004) The flavonoid baicalein inhibits fibrillation of alpha-synuclein and disaggregates existing fibrils. J Biol Chem 279(26): 26846-26857.

34. Palhano FL, Lee J, Grimster NP, Kelly JW (2013) Toward the molecular mechanism(s) by which EGCG treatment remodels mature Amyloid fibrils. J Am Chem Soc 135(20): 7503-7510.

35. Ishii T, Mori T, Tanaka T, Mizuno D, Yamaji R, et al. (2008) Covalent modification of proteins by green tea polyphenol (-)-epigallocatechin3-gallate through autoxidation. Free Radic Biol Med 45(10): 1384-1394.

36. Meng X, Munishkina LA, Fink AL, Uversky VN (2009) Molecular mechanisms underlying the flavonoid-induced inhibition of alphasynuclein fibrillation. Biochemistry 48(34): 8206-8224.

37. Hong DP, Fink AL, Uversky VN (2008) Structural characteristics of alphasynuclein oligomers stabilized by the flavonoid baicalein. J Mol Biol 383(1): 214-223

38. George RC, Lew J, Graves DJ (2013) Interaction of cinnamaldehyde and epicatechin with tau: implications of beneficial effects in modulating Alzheimer's disease pathogenesis. J Alzheimers Dis 36(1): 21-40.

39. Li W, Sperry JB, Crowe A, Trojanowski JQ, Smith AB, et al. (2009) Inhibition of tau fibrillization by oleocanthal via reaction with the amino groups of taus. J Neurochem 110(4):1339-1351.

40. Landau M, Sawaya MR, Faull KF, Laganowsky A, Jiang L, et al. (2011) Towards a pharmacophore for amyloid. PloS Biol 9(6).

41. Cao P, Raleigh DP (2012) Analysis of the inhibition and remodeling of islet amyloid polypeptide amyloid fibers by flavanols. Biochemistry 51(13): 2670-2683. 
42. Tu LH, Young LM, Wong AG, Ashcroft AE, Radford SE, et al. (2015) Mutational analysis of the ability of resveratrol to inhibit amyloid formation by islet amyloid polypeptide: critical evaluation of the importance of aromatic-inhibitor and histidine-inhibitor interactions. Biochemistry 54(3): 666-676.

43. Cheng B, Gong H, Xiao H, Petersen RB, Zheng L, et al. (2013) Inhibiting toxic aggregation of amyloidogenic proteins: a therapeutic strategy for protein misfolding diseases. Biochim Biophys Acta 1830(10): 48604871.

44. Popovych N, Brender JR, Soong R, Vivekanandan S, Hartman K, et al. (2012) Site specific interaction of the polyphenol EGCG with the SEVI amyloid precursor peptide PAP (248-286). J Phys Chem B 116(11): 3650-3658.

45. Ehrnhoefer DE, Bieschke J, Boeddrich A, Herbst M, Masino L, et al. (2008) EGCG redirects amyloidogenic polypeptides into unstructured, off-pathway oligomers. Nat Struct Mol Biol 15(6): 558-566.

46. Thapa A, Jett SD, Chi EY (2016) Curcumin attentuates amyloid-beta aggregate toxicity and modulates amyloid-beta aggregation pathway. ACS Chem Neurosci 7(1): 56-68.

47. Jha NN, Ghosh D, Das S, Anoop A, Jacob RS, et al. (2016) Effect of curcumin analogs on alpha-synuclein aggregation and cytotoxicity. Scientific Reports 6.

48. Liu G, Gaines JC, Robbins KJ, Lazo ND (2012) Kinetic profile of amyloid formation in the presence of an aromatic inhibitor by nuclear magnetic resonance. ACS Med Chem Lett 3(10): 856-859.

49. Nelson KM, Dahlin JL, Bisson J, Graham J, Pauli GF, et al. (2017) The essential medicinal chemistry of curcumin. J Med Chem 60(5): 16201637.

50. Guerrero-Munoz MJ, Castillo-Carranza DL, Kayed R (2014) Therapeutic approaches against common structural features of toxic oligomers shared by multiple amyloidogenic proteins. Biochem Pharmacol 88(4): 468-478.

51. Nedumpully Govindan P, Kakinen A, Pilkington EH, Davis TP, Ke PC, et al. (2016) Stabilizing off-pathway oligomers by polyphenol nanoassemblies for IAPP aggregation inhibition. Scientific Reports 6.

52. Ono K, Hasegawa K, Naiki H, Yamada M (2004) Curcumin has potent anti-amyloidogenic effects for Alzheimer's beta-amyloid fibrils in vitro J Neurosci Res 75(6): 742-750.

53. Yang F, Lim GP, Begum AN, Ubeda OH, Simmons MR, et al. (2005) Curcumin inhibits formation of amyloid beta oligomers and fibrils, binds plaques, and reduces amyloid in vivo. J Biol Chem 280(7): 5892-5901.

54. Singh PK, Kotia V, Ghosh D, Mohite GM, Kumar A, et al. (2013) Curcumin modulates $\alpha$-synuclein aggregation and toxicity. ACS Chem Neurosci 4(3): 393-407.

55. Bieschke J, Russ J, Friedrich RP, Ehrnhoefer DE, Wobst H, et al. (2010) EGCG remodels mature $\alpha$-synuclein and amyloid- $\beta$ fibrils and reduces cellular toxicity. Proc Natl Acad Sci U S A 107(17): 7710-7715.

56. Lopez del Amo JM, Fink U, Dasari M, Grelle G, Wanker EE, et al. (2012) Structural properties of EGCG-induced, nontoxic Alzheimer's disease Abeta oligomers. J Mol Biol 421(4-5): 517-524.

57. Engel MF, VandenAkker CC, Schleeger M, Velikov KP, Koenderink GH, et al. (2012) The polyphenol EGCG inhibits amyloid formation less efficiently at phospholipid interfaces than in bulk solution. J Am Chem Soc 134(36): 14781-14788.

58. Dhouafli Z, Cuanalo-Contreras K, Hayouni EA, Mays CE, Soto C, et al. (2018) Inhibition of protein misfolding and aggregation by natural phenolic compounds. Cell Mol Life Sci 75: 3521-3538.

59. Dobson CM (1999) Protein misfolding, evolution and disease. Trends Biochem Sci 24(9): 329-332.

60. Duran Aniotz C, Moreno-Gonzalez I, Morales R (2013) Amyloid aggregates: role in protein misfolding disorders. Rev Med Chile 141(4): 495-505.
61. Moreno-Gonzalez I, Soto C (2011) Misfolded protein aggregates: mechanisms, structures and potential for disease transmission. Semin Cell Dev Biol 22(5): 482-487.

62. Soto C (2003) Unfolding the role of protein misfolding in neurodegenerative diseases. Nat Rev Neurosci 4(1): 49-60.

63. Duyckaerts C, Delatour B, Potier MC (2009) Classification and basic pathology of Alzheimer disease. Acta Neuropathol 118(1): 5-36.

64. Samii A, Nutt JG, Ransom BR (2004) Parkinson disease. Lancet 363 (9423): 1783-1793.

65. Hetz C, Soto C (2003) Protein misfolding and disease: the case of prion disorders. Cell Mol Life Sci 60(1): 133-143.

66. Taylor JP, Brown RH, Cleveland DW (2016) Decoding ALS: from genes to mechanism. Nature 539(7628): 197-206.

67. Brauer S, Zimyanin V, Hermann A (2018) Prion-like properties of disease-relevant proteins in amyotrophic lateral sclerosis. J Neural Transm 125(4): 591-613.

68. Lau DH, Hartopp N, Welsh NJ, Mueller S, Glennon EB, et al. (2018) Disruption of ER-mitochondria signalling in fronto-temporal dementia and related amyotrophic lateral sclerosis. Cell Death Dis 9(3): 327.

69. Mackenzie IR, Neumann M, Baborie A, Sampathu DM, Du Plessis D, et al. (2011) A harmonized classification system for FTLD-TDP pathology. Acta Neuropathol 122(1): 111-113.

70. Ross CA, Tabrizi SJ (2011) Huntington's disease: from molecular pathogenesis to clinical treatment. Lancet Neurol 10(1): 83-98.

71. Andre R, Tabrizi SJ (2012) Misfolded PrP and a novel mechanism of proteasome inhibition. Prion 6(1): 32-36.

72. Tai HC, Serrano-Pozo A, Hashimoto T, Frosch MP, Spires-Jones TL, et al. (2012) The synaptic accumulation of hyperphosphorylated tau oligomers in Alzheimer disease is associated with dysfunction of the ubiquitin-proteasome system. Am J Pathol 181(4): 1426-1435.

73. Cuanalo Contreras K, Mukherjee A, Soto C (2013) Role of protein misfolding and proteostasis deficiency in protein misfolding diseases and aging. International Journal of Cell Biology p.10.

74. Lee JH, Yu WH, Kumar A, Lee S, Mohan PS, et al. (2010) Lysosomal proteolysis and autophagy require presenilin 1 and are disrupted by Alzheimer-related PS1 mutations. Cell 141(7): 1146-1158.

75. Nixon RA, Yang DS, Lee JH (2008) Neurodegenerative lysosomal disorders: a continuum from development to late age. Autophagy 4(5): 590-599.

76. Sanchez Varo R, Trujillo Estrada L, Sanchez Mejias E, Torres M, Baglietto Vargas D, et al. (2012) Abnormal accumulation of autophagic vesicles correlates with axonal and synaptic pathology in young Alzheimer's mice hippocampus. Acta Neuropathol 123(1): 53-70.

77. Nelson R, Sawaya MR, Balbirnie M, Madsen AO, Riekel C, et al. (2005) Structure of the cross-beta spine of amyloid-like fibrils. Nature 435(7043): 773-778.

78. Kelly JW (1996) Alternative conformations of amyloidogenic proteins govern their behavior. Curr Opin Struct Biol 6(1): 11-17.

79. De la Luz Cadiz-Gurrea M, Fernandez-Arroyo S, Segura-Carretero A (2014) Pine bark and green tea concentrated extracts: antioxidant activity and comprehensive characterization of bioactive compounds by HPLC-ESI-QTOF-MS. Int J Mol Sci 15(11): 20382-20402.

80. Betts JW, Sharili AS, Phee LM, Wareham DW (2015) In vitro activity of epigallocatechin gallate and quercetin alone and in combination versus clinical isolates of methicillin-resistant Staphylococcus aureus. J Nat Prod 78(8): 2145-2148.

81. BituPinto N, DaSilva AB, Neves KRT, Silva AH, Leal LK, et al. (2015) Neuroprotective properties of the standardized extract from Camellia sinensis (green tea) and its main bioactive components, epicatechin and 
epigallocatechin gallate, in the 6-OHDA model of Parkinson's disease. Evid Based Complement Alternat Med 2015: (161092).

82. Bieschke J, Russ J, Friedrich RP, Ehrnhoefer DE, Wobst H, et al. (2008) EGCG redirects amyloidogenic polypeptides into unstructured, offpathway oligomers. Nat Struct Mol Biol 15(6): 558-566.

83. Wobst HJ, Sharma A, Diamond MI, Wanker EE, Bieschke J (2015) The green tea polyphenol (-)-epigallocatechin gallate prevents the aggregation of tau protein into toxic oligomers at sub stoichiometric ratios. FEBS Lett 589(1): 77-83.

84. Ghosh S, Banerjee S, Sil PC (2015) The beneficial role of curcumin on inflammation, diabetes and neurodegenerative disease: a recent update. Food Chem Toxicol 83: 111-124.

85. He Y, Yue Y, Zheng X, Zhang K, Chen S, et al. (2015) Curcumin, inflammation, and chronic diseases: how are they linked? Molecules 20(5): 9183-9213.

86. Lin C-F, Yu K H, Jheng C P, Chung R, Lee C I (2013) Curcumin reduces amyloid fibrillation of prion protein and decreases reactive oxidative stress. Pathogens 2(3): 506-519.

87. pinelli KJ, Osterberg VR, Meshul CK, Soumyanath A, Unni VK (2015) Curcumin treatment improves motor behavior in $\alpha$-synuclein transgenic mice. PloS One 10(6): e0128510.

88. Yanagisawa D, Shirai N, Amatsubo T, Taguchi H, Hirao K, et al. (2010) Relationship between the tautomeric structures of curcumin derivatives and their Abeta-binding activities in the context of therapies for Alzheimer's disease. Biomaterials 31(14): 4179-4185.

89. Yang F, Lim GP, Begum AN, Ubeda OJ, Simmons MR, et al. (2005) Curcumin inhibits formation of amyloid beta oligomers and fibrils, binds plaques, and reduces amyloid in vivo. J Biol Chem 280(7): 5892-5901.

90. Ladiwala ARA, Lin JC, Bale SS, Marcelino-Cruz AM, Bhattacharya M, et al. (2010) Resveratrol selectively remodels soluble oligomers and fibrils of amyloid Abeta into off-pathway conformers. J Biol Chem 285(31): 24228-24237.
91. Ge JF, Qiao JP, Qi CC, Wang CW Zhou JN (2012) The binding of resveratrol to monomer and fibril amyloid beta. Neurochem Int 61(7): 1192-1201.

92. Feng Y, Wang XP, Yang SG, Wang YJ, Zhang X, et al. (2009) Resveratrol inhibits beta-amyloid oligomeric cytotoxicity but does not prevent oligomer formation. Neurotoxicology 30(6): 986-995.

93. He X, Li Z, Rizak JD, Wu S, Zhengbo Wang, et al. (2016) Resveratrol attenuates formaldehyde induced hyperphosphorylation of tau protein and cytotoxicity in N2a cells. Front Neurosci 31(10): 598.

94. Karuppagounder SS, Pinto JT, Xu H, Chen HL, Beal MF, et al. (2009) Dietary supplementation with Resveratrol reduces plaque pathology in a transgenic model of Alzheimer's disease. Neurochem Int 54(2): 111118.

95. Marambaud P, Zhao H, Davies P (2005) Resveratrol promotes clearance of Alzheimer's disease amyloid-beta peptides. J Biol Chem 280(45): 37377-37382

96. Wang R, Zhang Y, Li J, Zhang C (2017) Resveratrol ameliorates spatial learning memory impairment induced by $A \beta 1-42$ in rats. Neurosci 344 : 39-47.

97. Porquet D, Grinan-Ferre C, Ferrer I, Camins A, Sanfeliu C, et al. (2014) Neuroprotective role of trans-resveratrol in a murine model of familial Alzheimer's disease. J Alzheimers Dis 42(4): 1209-1220.

98. Zhao HF, Li N, Wang Q, Cheng XJ, Li XM, et al. (2015) Resveratrol decreases the insoluble $A \beta 1-42$ level in hippocampus and protects the integrity of the blood brain barrier in AD rats. Neuroscience 310: 641-649.

99. Yao Y, Li J, Niu Y, Yu J, Yan L, et al. (2015) Resveratrol inhibits oligomeric Abeta-induced microglial activation via NADPH oxidase. Med. Mol Med Rep 12(4): 6133-6139.

100. Huang TC, Lu KT, Wo YYP, Wu YJ, Yang YL (2011) Resveratrol protects rats from $A \beta$-induced neurotoxicity by the reduction of iNOS expression and lipid peroxidation. PloS One 6(12): e29109.

101. Angela Botes, Anthony J Sinskey Department of Biology, Massachusetts Institute of Technology, USA. 